\title{
A importância dos sistemas geodésicas de referência no cadastramento rural
}

\section{The importance of the reference systems in rural registration}

Felipe Gomes Rubira* Georgea do Vale de Melo **

Gustavo Fonseca***

\section{Resumo:}

O objetivo desta pesquisa consiste em discutir as principais ações envolvendo os SGR para o cadastramento de imóveis rurais por meio da lei no $10.267 / 01$, que determinou a criação de um cadastro imobiliário rural obrigatório. A metodologia empregada baseou-se em reflexões teóricas através de pesquisa bibliográfica. Os resultados evidenciaram a importância dos Sistemas de Referências Brasileiros para o desmembramento, parcelamento ou remembramento de imóveis rurais. Concluiu-se que os sistemas geodésicos são imprescindíveis para o pleno sucesso de cadastramento e mapeamento dos limites territoriais de imóveis rurais. Com eles foram evitados vários problemas como sobreposição de áreas, grilagem de terras e a formação ilegal de latifúndios no Brasil, coibindo a apropriação irregular e a transferência fraudulenta de terras. Concluiu-se que a mudança de um sistema de origem topocêntrica (Córrego Alegre e SAD 69) para geocêntrica (SIRGAS 2000) trouxe uma série de benefícios e vantagens.

\footnotetext{
* Universidade Federal de Alfenas (UNIFAL) - Doutorando em Geografia pela UNICAMP

** Graduada em Geografia pela Universidade Estadual de Maringá (UEM)

*** Graduado em Geografia pela Universidade Estadual de Maringá (UEM)
}

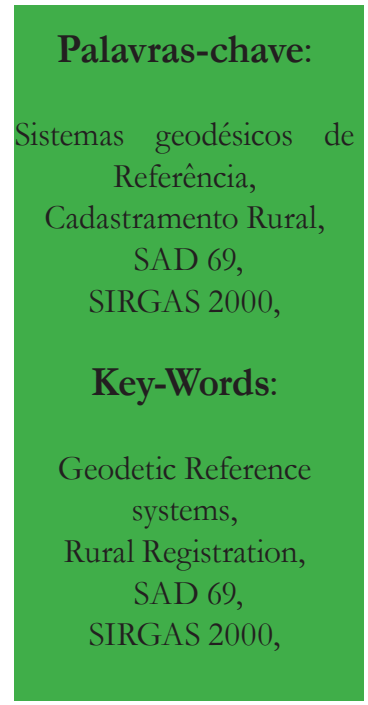

\section{Abstract:}

The objective of this research is to discuss the main actions involving the SGR for registration of rural properties by Law $n^{\circ}$. 10.267/01, which led to the creation of a mandatory rural real estate cadastre. The methodology was based on theoretical reflections through literature. The results showed the importance of the Brazilian Reference Systems for the break up, or remembramento installment of rural properties. It was concluded that the geodetic systems are essential to the full success of registration and mapping the boundaries of rural properties. With them have been avoided several problems like overlapping areas, land grabbing and illegal formation of latifundia in Brazil, curbing ownership irregular and fraudulent transfer of land. It was concluded that the change of a topocentric source system (Alegre Stream and SAD 69) to geocentric (SIRGAS 2000) brought a number of benefits and advantages. 


\section{INTRODUÇÃO}

A tualmente, verifica-se que a utilização dos Sistemas Geodésicos de Referência (SGR) torna-se imprescindível para elaboração de trabalhos que envolvem a área de geoprocessamento e georreferenciamento.

O primeiro Sistema de Referência Brasileiro (SRB) foi implantado pelo Instituto Brasileiro de Geografia e Estatística (IBGE) em 17 de maio de 1944. Desde então vem sendo amplamente utilizado por usuários que necessitam de informações posicionais para diversos trabalhos de geoprocessamento, que tenham como objetivos o apoio ao mapeamento, demarcação de unidades político-administrativas, obras de engenharia, regulamentação fundiária, posicionamento de plataformas de prospecção de petróleo, delimitação de regiões de pesquisas geofísicas entre outros (PEREIRA; AUGUSTO, 2004).

Os principais sistemas geodésicos brasileiros que serão abordados na pesquisa são: o Sistema de Referência Córrego Alegre, o South American Datum (SAD 69) e o Sistema de Referências Geocêntrico para as Américas (SIRGAS 2000).

$\mathrm{O}$ objetivo da pesquisa consiste em discutir as principais ações e relações envolvendo os SRB para o cadastramento de imóveis rurais por meio da lei $\mathrm{n}^{\circ}$ 10.267 de 28 de agosto de 2001, que determinou a criação de um cadastro imobiliário rural obrigatório. Simultaneamente, objetiva-se destacar a partir da revisão de literatura, as etapas necessárias para o estabelecimento do SGR, as principais características dos sistemas de referências brasileiros que foram adotados ao longo da história, destacando suas funcionalidades e pontos positivos.

A referida lei determina a realização de um levantamento dos imóveis rurais em todo o país, sob responsabilidade de fiscalização do Instituto Nacional de Colonização e Reforma Agrária (INCRA). Uma das determinações para que se realize corretamente o cadastramento de imóveis rurais é a utilização dos sistemas geodésicos de referência, principalmente no tocante a fase de georreferenciamento, delimitando a área exata da propriedade, evitando sobreposição de áreas.

A lei no 10.267/01 também criou uma norma técnica para o georreferenciamento de imóveis rurais (BRASIL, 2010), elaborada com o intuito de orientar os profissionais que atuam no mercado de georreferenciamento de imóveis rurais.

A pesquisa envolve também, alguns conceitos essenciais para que se compreenda a funcionalidade e aplicação dos sistemas de referências em trabalhos de georreferenciamento, como as superfícies de referência (superfície física, geoide e elipsoide), Altitude Elipsoidal (h) e Altitude Ortométrica (H) e Datum Planimétrico e Altimétrico inseridos em rede planimétricas e altimétricas.

De maneira sucinta, os sistemas geodésicos de referência podem ser definidos como um sistema de coordenadas que está intimamente relacionado a quaisquer características terrestres.

Esta pesquisa torna-se importante, pois oferece noções essenciais para o correto cadastramento de imóveis rurais por meio da utilização de sistemas geodésicos de referência com base na lei n ${ }^{\circ} 10.267 / 01$ e sua respectiva norma técnica. Também se apresenta importante por focar a importância de se definir um sistema único para todo país. Da mesma maneira, esta pesquisa justifica-se no atual cenário em que a realização do $\mathrm{Ca}$ dastro Ambiental Rural (CAR) se tornou obrigatória, utilizando-se também dos SGR para sua realização.

\section{METODOLOGIA}

Este artigo baseou-se em reflexões teóricas sobre as relações que envolvem os sistemas de referências brasileiros e o processo de cadastramento dos imóveis rurais. Portanto, o procedimento metodológico utilizado foi a pesquisa bibliográfica, por meio de trabalhos publicados em congressos, periódicos, livros, dissertações e teses.

Ao longo da pesquisa de caráter qualitativo foram expostas discussões sobre a importância dos Sistemas Geodésicos de Referência para o cadastramento de imóveis rurais com base na lei no 10.267/01.

Por meio do fluxograma metodológico elaborado (Figura 1) pode-se visualizar os principais pontos de abordagem da pesquisa.

Primeiramente foram definidos alguns conceitos correlatos, essenciais para o pleno entendimento das etapas responsáveis pelo estabelecimento dos SGR (definição, materialização e densificação). Após esta discussão inicial, com base na bibliografia utilizada, foram detalhadas as particularidades dos principais Sistemas 
Geodésicos Brasileiros, simultaneamente foram realizadas algumas comparações.

Após a elucidação das principais funcionalidades e características dos SGR, relacionou-se a importância dos mesmos para o cadastramento dos imóveis rurais, por meio das regulamentações da lei $n^{\circ} 10.267 / 01$, consultas bibliográficas e reflexões teóricas realizadas. orientado". Para a autora a realização de um SGR só é possível ser efetuada através de um conjunto de pontos implantados sobre a superfície física da terra com coordenadas conhecidas.

Volpi (2007, p. 23), com mesmo raciocínio determina que "para identificar a posição de uma determinada informação ou de um objeto, são utilizados os sistemas de referência".

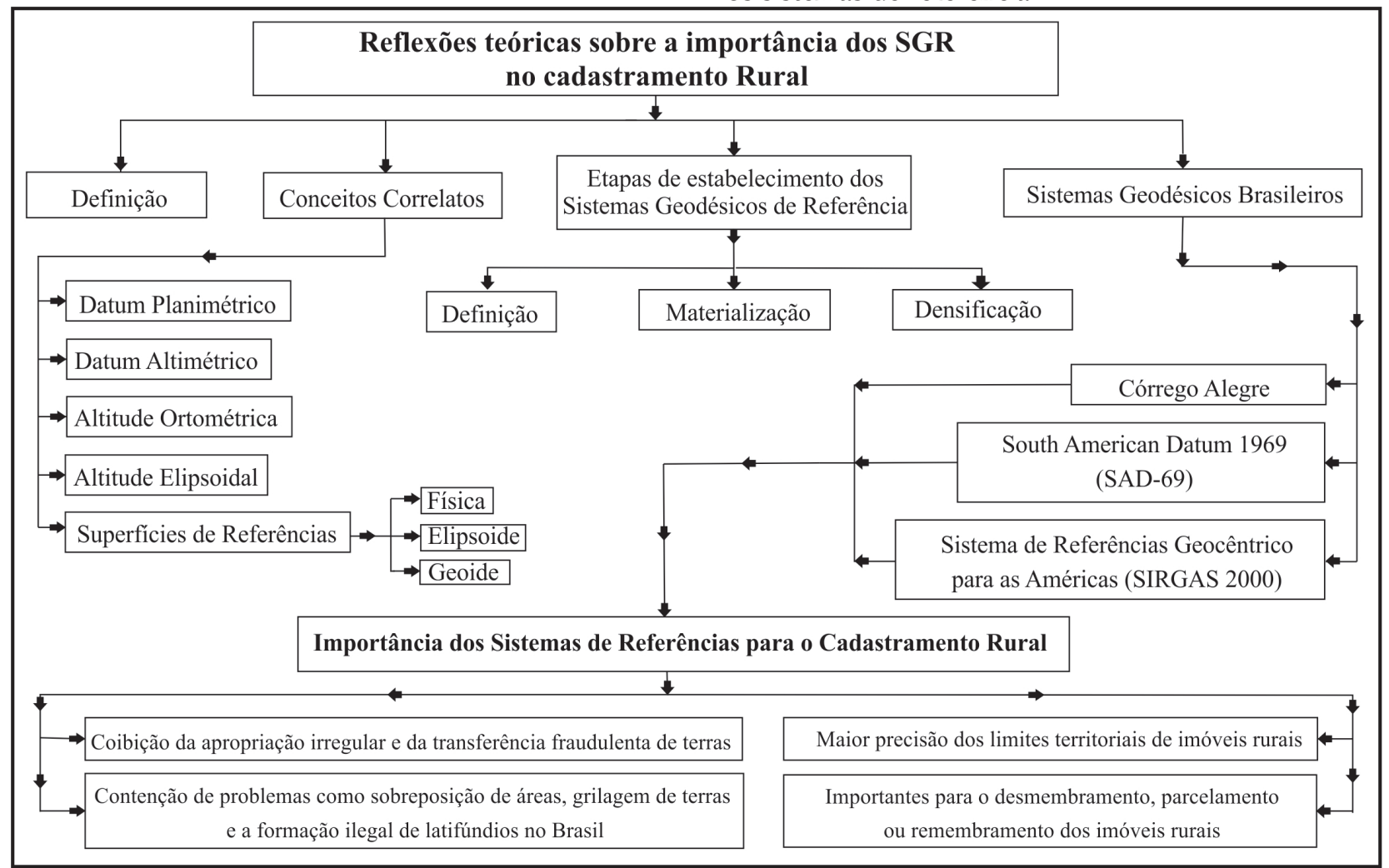

Figura 1: Fluxograma metodológico

\section{RESULTADOS E DISCUSSÕES}

Nesta parte da pesquisa serão expostas as principais discussões sobre as bases teóricas essenciais para a realização do trabalho, os fundamentos teóricos e conceitos que nortearam a pesquisa, intrinsecamente com os resultados provenientes das análises literárias.

3.1 Definições, etapas de estabelecimento dos sistemas geodésicos de referência e alguns conceitos correlatos

Para Dalazoana (2001, p. 7), um SGR “caracterizase por um conjunto de convenções junto a um elipsoide ajustado às dimensões da Terra e devidamente
McCartthy (1996) salienta que os sistemas de referência são um sistema de coordenadas que estão intimamente relacionados a quaisquer características terrestres que englobe as determinadas etapas de definição, materialização e densificação dessas mesmas características, que podem variar de acordo com o objetivo de cada trabalho, no caso desta pesquisa, o cadastramento de imóveis rurais.

Dentro desta ótica, McCartthy (1996) caracteriza o papel das três etapas por ele apontadas. Seguindo o ponto de vista ideológico do autor, a primeira etapa, de definição, consiste na compreensão da ideia conceitual de um elipsoide de revolução, o qual envolve modelos matemáticos e físicos essenciais para a aplicação das injunções de posição e orientação espacial. 
A segunda etapa de materialização ou realização, consiste em estabelecer um conjunto de estações geodésicas associadas as suas respectivas coordenadas, velocidades e precisões. A terceira etapa, de densificação, segundo McCartthy (1996) é a responsável pela composição das referências continentais, nacionais ou regionais espalhadas pelo globo terrestre.

Deste modo, de acordo com as etapas estabelecidas por McCartthy (1996), Monico (2000) argumenta que:

\footnotetext{
Quando um referencial é definido e adotado por convenção, a etapa seguinte é caracterizada pela coleta de observações a partir de pontos sobre a superfície terrestre (rede), devidamente materializados. Fazem parte, ainda, o processamento e análise, bem como a divulgação dos resultados, que é, essencialmente, um conjunto de coordenadas associado a uma época em particular. As coordenadas podem vir acompanhadas de suas respectivas velocidades. Esse conjunto materializa o sistema de referência. (MONICO, 2000, p. 60)
}

Relacionando às três etapas acima mencionadas para a concretização de um SGR, Oliveira (1998), de encontro com as ideias de McCartthy (1996), Monico (2000) e Dalazoana (2001), determina quatro etapas racionais necessárias para o estabelecimento de um SGR, a conceituação, a definição, a materialização e a densificação.

Do ponto de vista conceitual do SGR é visualizada a origem do sistema e fixação dos eixos. Blitzkow et al. (2011) com base nos estudos de Oliveira (1998) afirma que "Do ponto de vista conceitual um referencial ideal seria aquele em que a origem seguisse a lei newtoniana da inércia (mantivesse-se em repouso ou em movimento retilíneo uniforme)". (BLITZKOW et. al. 2011, p. 637).

Quanto à etapa de definição, Blitzkow et al. (2011) evidencia que para que seja possível a realização de comparações entre os referenciais:

é necessário adotar "convencionalmente" uma definição do referencial. Para isso são estabelecidos princípios que fixam a origem, a orientação dos eixos e a escala de sistemas de coordenadas. Através de observações levadas a efeito a partir de pontos devidamente materializados sobre a superfície da Terra e conduzidos sobre objetos adequados para o caso, estabelece-se um conjunto de coordenadas de referência para os pontos. Este conjunto de pontos constitui uma rede de referência, de caráter global, utilizada para vincular outras determinações. (BLITZKOW et. al. 2011, p. 637).

Nesse particular, é importante ressaltar as considerações de Dalazoana (2001, p. 15), as quais enfatizam que a etapa de materialização, do funcionamento de um SGR, somente é possível ser concluída por meio de um conjunto de pontos implantados sobre a superfície física da Terra, cujas coordenadas são conhecidas. Portanto, a realização do sistema de referência somente é disponibilizada ao usuário por meio da existência e divulgação de um conjunto de coordenadas.

$\mathrm{Na}$ etapa final de densificação, Blitzkow et al. (2011) especifica como se caracteriza o processo:

\begin{abstract}
As redes com características globais implicam numa distribuição de pontos separados por centenas e até milhares de quilômetros. As necessidades práticas, bem como as técnicas de obtenção de coordenadas vinculadas a uma referência global, exigem o estabelecimento de redes com um espaçamento da ordem de poucas dezenas de quilômetros entre os pontos materializados. Isto implica na implantação de pontos de densificação, os quais compõem as redes de referência continentais, nacionais ou regionais (BLITZKOW et. al. 2011, p. 637-638).
\end{abstract}

Neste momento, torna-se importante frisar, de acordo com Dalazoana (2001), a necessidade e importância que os SGR exercem para as instituições e empresas, principalmente as voltadas para a produção cartográfica, ressaltando que "é de extrema importância o conhecimento das características e restrições de cada um destes sistemas". (DALAZOANA, 2001, p. 7).

Portanto, presenciamos o ponto de vista de alguns autores que buscaram definir o que é um SGR, utilizando a proposta das quatro etapas mencionadas para o estabelecimento do mesmo, as etapas de conceituação, definição, materialização e densificação.

Cabe neste momento da pesquisa estabelecer alguns conceitos que compõem toda a discussão relacionada aos sistemas de referência: as superfícies de referência, utilizadas para distinguir coordenadas curvilíneas e altitudes obrigatórias; a altitude ortométrica e elipsoidal; o datum altimétrico e o datum planimétrico.

São conhecidas três superfícies de referências, a física, o elipsoide e o geoide, os conceitos serão definidos e caracterizados a partir deste momento.

Roque et al. (2006, p. 92) caracteriza a superfície física como a superfície real, ou seja, uma superfície entre as massas sólidas ou fluídas e a atmosfera, os autores destacam que é nesta superfície de referência que são realizadas as medidas topográficas, nivelamentos e é onde estão posicionados os receptores GPS.

O elipsoide para Roque et al. (2006, p. 92) é "a 
figura matemática que imita a forma real da Terra. Sua finalidade é possibilitar cálculos que seriam impossíveis para a superfície disforme do globo terrestre". Para Dalazoana (2001, p. 11) "O elipsoide devidamente ajustado às dimensões da Terra e orientado torna-se um referencial adequado para a atribuição de coordenadas a pontos sobre a superfície física da Terra.".

Sobre a posição e orientação, os elipsoides podem envolver a Terra toda ou certa região, como um país, um grupo de países ou continente.

Para Costa (1999, p. 17) os elipsoides que abrangem todo o planeta são denominados de elipsoides geocêntricos, o centro geométrico é coincidente com o centro de massa da Terra para uma dada época.

Os que abrangem um país, um grupo de países ou continente são denominados de elipsoides topocêntricos, o centro do elipsoide (ou origem dos eixos) não está localizado no centro de massa da Terra, mas sim no ponto de origem (vértice) escolhido. Segundo Costa (1999) a orientação dos elipsoides topocêntricos é realizada por meio das coordenadas de um ponto origem, da orientação (azimute inicial), da separação geoideelipsoide (ondulação geoidal), e das componentes do desvio da vertical.

Quanto ao conceito de geoide, Volpi (2007, p. 13) define como "uma superfície irregular com saliências e "buracos" ocasionado pela maior ou menor concentração de massa no interior da Terra".

Para Silveira (2005), geoide significa "forma da Terra", delimitada pela linha do prolongamento do nível médio dos mares nos continentes, o autor considera que esta linha é a representação mais próxima da realidade física expressa pelo campo gravitacional terrestre.

É necessário ressaltar sobre as superfícies de referência, a expressão ondulação geoidal. Segundo Dalazoana (2001) ondulação geoidal é a separação entre as superfícies do geoide (superfície que representa o nível médio dos mares) e elipsoide (modelo matemático usado para a representação da Terra).

D’Alge (2001) afirma que a melhor aproximação dessa Terra matematicamente tratável é o geoide, definindo-o como a superfície equipotencial do campo da gravidade terrestre que mais se aproxima do nível médio dos mares.

É possível verificar um modelo que indica a sobreposição das três superfícies de referência da ciência geodésica em um mesmo espaço (Figura 2).

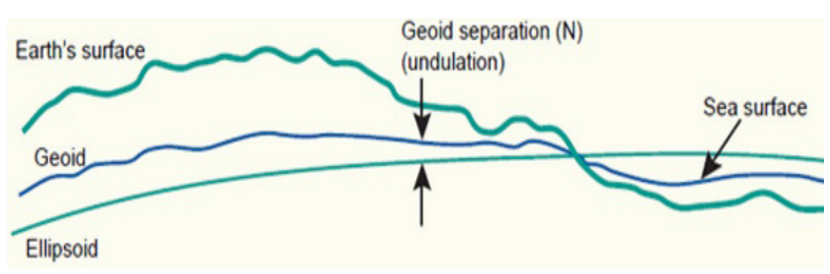

Figura 2: Superfície Física, Geoide e Elipsoide

Fonte: http://kartoweb.itc.nl/geometrics/reference\%20surfaces/ body.htm

A Altitude Elipsoidal (h) se refere à medição que parte de um ponto na linha do elipsoide (Figura 3). É a distância vertical de qualquer ponto ao elipsoide medida ao longo da perpendicular que passa por aquele ponto, é válido ressaltar que as altitudes indicadas pelos receptores dos Sistemas de Posicionamento Global (GPS), por exemplo, são do tipo elipsoidal.

A Altitude Ortométrica $(\mathrm{H})$ se refere ao nível médio do mar (Figura 3). É a distância vertical de um ponto, situado sobre a superfície terrestre em relação a um geoide de referência. É perfeitamente possível converter altitudes elipsoidais em ortométricas ou vice e versa.
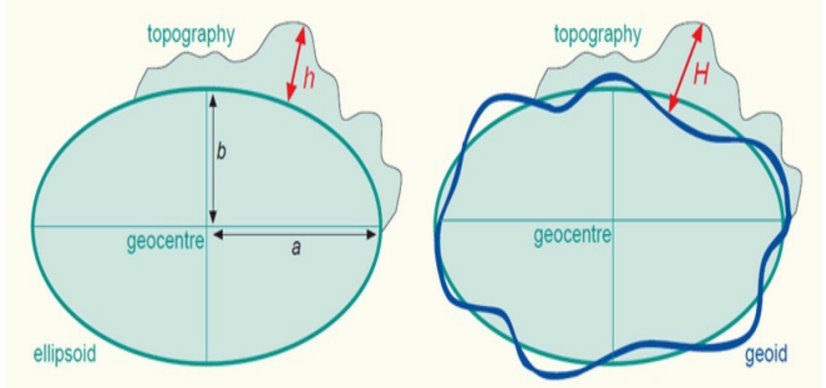

Figura 3: Altitude Elipsoidal (h) e Altitude Ortométrica (H). Fonte: http://kartoweb.itc.nl/geometrics/reference\%20surfaces/ body.htm

Outro conceito necessário para compreensão das funcionalidades dos sistemas de referência e para elaboração de trabalhos de georreferenciamento é o de Datum Altimétrico e Datum Planimétrico.

Podem ser tanto horizontais como verticais. São essenciais para trabalhos geodésicos, já que são utilizados para referência dos mesmos, são definidos basicamente por três variáveis, a latitude e longitude de um ponto inicial e o azimute de uma linha que parte deste mesmo ponto, o datum pode ser local, regional ou global.

O Datum Altimétrico ou vertical, associado a uma rede altimétrica, é definido por Blitzkow et al. (2011) como sendo a superfície de referência usada para 
definir as altitudes de pontos da superfície terrestre. É a Superfície de referência para as altitudes do tipo Ortométrica ou Elipsoidal.

Quanto ao Datum Planimétrico ou horizontal, associado a uma rede planimétrica, é definido por D’Alge (2001, p. 12-13) como sendo “[...] a superfície de referência elipsoidal posicionada com respeito a uma certa região. Sobre esta superfície realizam-se as medições geodésicas que dão vida à rede geodésica planimétrica da região.”. Portanto, Datum Planimétrico constitui-se como a referência para o posicionamento horizontal.

A partir da revisão acerca das definições, das etapas de funcionamento e da breve revisão dos principais conceitos associados aos sistemas geodésicos de referência, torna-se possível a partir deste momento, realizar uma análise sobre as funcionalidades dos sistemas geodésicos adotados no Brasil ao longo da história.

\subsection{Os sistemas geodésicos brasileiros de referência}

Nesta parte da pesquisa torna-se necessário evidenciar alguns exemplos de SGR, especificar as características dos SGR em atividade no Brasil, os três principais, mais utilizados pelos usuários e empresas, principalmente para as instituições voltadas à produção cartográfica e trabalhos de georreferenciamento, necessários e indispensáveis para a realização de um trabalho de cadastro técnico de imóveis rurais.

Pereira e Augusto (2004) mencionam a iniciativa do Instituto Brasileiro de Geografia e Estatística (IBGE), que em 1944 iniciou a implantação do primeiro Sistema Geodésico Brasileiro, o qual vem sendo utilizado até os dias atuais para diversos fins como, por exemplo, "apoio ao mapeamento, demarcação de unidades político-administrativas, obras de engenharia, regulamentação fundiária, posicionamento de plataformas de prospecção de petróleo, delimitação de regiões de pesquisas geofísicas" (PEREIRA; AUGUSTO, 2004, p. 2).

Os SGR adotados no território brasileiro ao longo da história são: o Córrego Alegre, o South American Datum (SAD 69) e o Sistema de Referências Geocêntrico para as Américas (SIRGAS 2000).

Moraes et al. (2008) destacam a mudança dos sistemas de referência no Brasil ao longo do tempo, de origem topocêntrica para geocêntrica, que segundo os autores acarretou em alterações nas coordenadas da rede geodésica.

Em função disso, Moraes et al. (2008, p.1) relatam que a maior parte dos produtos cartográficos no Brasil ainda são referenciados ao sistema Córrego Alegre e SAD 69, de origem topocêntrica. Torna-se importante então compreender esta mudança, para que seja possível utilizar o sistema do tipo geocêntrico, o SIRGAS 2000, a partir das transformações entre os sistemas de referência.

Nessa perspectiva, Chuerubim (2009) ressalta que:

muitos dos trabalhos cartográficos desenvolvidos no país encontram-se referenciados ao Córrego Alegre e ao SAD69, o que implica na necessidade de transformações entre sistemas de referência com concepções e realizações diferentes (CHUERUBIM, 2009, p. 41).

De acordo com Chuerubim (2009), o Instituto Brasileiro de Geografia e Estatística (IBGE), apresentase como órgão responsável por estabelecer e manter o Sistema Geodésico Brasileiro (SGB), caracterizado pelo conjunto de estações geodésicas, que representam o controle horizontal e vertical necessários ao desenvolvimento de obras de infraestrutura no território nacional.

Dalazoana (2001, p. 19) afirma que a materialização de um SGB acontece por meio das Redes Geodésicas Brasileiras (RGB) que se constituem basicamente em três, a Rede Horizontal, a Rede Vertical e a Rede Tridimensional, formadas pelos conjuntos de estações e coordenadas geodésicas.

Define-se por Sistema Geodésico Brasileiro “o conjunto de pontos geodésicos implantados na porção da superfície terrestre delimitada pelas fronteiras do país. Em outras palavras é o sistema ao qual estão referidas todas as informações espaciais no Brasil" (BRASIL, 1983, p. 1).

\subsubsection{Córrego Alegre}

O Sistema de referência Córrego Alegre, foi o primeiro sistema de referência brasileiro a ser adotado, mas que nos dias atuais ainda exerce importância, isso porque existe no território brasileiro um grande número de documentos cartográficos e coordenadas referidas a ele.

Magna Júnior (2007) define o sistema Córrego Alegre como um sistema de orientação topocêntrica que possui como ponto de origem o vértice de triangulação Córrego Alegre, posicionado astronomicamente. 
Dalazoana (2001) relata que o sistema com o datum Córrego Alegre, foi adotado pelo Brasil na década de 1940 até a década de 1970, sendo definido por meio do ajustamento de métodos correlatos ou equações de condição da rede horizontal do SGB.

Dentro dessas acepções, Volpi (2007) vai ao encontro das constatações de Dalazoana (2001) e Magna Júnior (2007) ao detalhar que o Brasil adotou durante muitos anos o Córrego Alegre como o sistema de referência oficial, sendo elaborado a partir de um vértice da triangulação, localizado nas imediações de Uberaba, o qual constituía a sua origem. É oportuno lembrarmos que:

apesar do Sistema Córrego Alegre não ser mais o sistema de referência oficial no Brasil, estas cartas vem sendo atualizadas e novos produtos vêm sendo gerados com base neste sistema. Além disso, o apoio terrestre e sua densificação, utilizados para a geração das cartas [...] também são utilizados para a geração de produtos em escalas maiores. A realização do Sistema Córrego Alegre de precisão compatível com as técnicas e equipamentos da época, aliada à menor precisão da densificação do apoio terrestre, faz com que os produtos gerados com base neste sistema, principalmente os em escalas grandes, percam em qualidade quando comparados aos produtos gerados com base em sistemas de referência e tecnologias mais atuais. (DALAZOANA, 2001, p. 19).

Quando a autora se refere a sistemas de referências mais atuais, pode-se mencionar como exemplo os sistemas de referências SAD 69 e SIRGAS 2000.

A afirmação de Dalazoana (2001) foi constatada na investigação realizada pelo IBGE (2000), a qual expõe dados essenciais que comprovam a importância dada ao sistema Córrego Alegre até os dias atuais, dados que demonstram a quantidade de cartas topográficas produzidas nesse sistema.

Segundo o IBGE (2000), na escala de 1: 1.000.000 foram produzidas 46 cartas; na escala de 1: 250.000 foram elaboradas um total de 320 cartas; na escala de 1 : 100.000, 1262 cartas; na escala de 1: 25.000, foram produzidas 148 cartas. Todas pelo Sistema Córrego Alegre, ou seja, 2.891 cartas que exercem grande importância até os dias atuais.

D'Alge (2001) delimita que o antigo Datum Planimétrico Córrego Alegre utiliza o elipsoide de Hayford de 1924, que na visão do autor sempre foi considerado o mais viável para o continente sul americano. As coordenadas geográficas que correspondem ao vértice Córrego Alegre são Latitude $(\gamma)$ 50’14,91" S e Longitude $(\lambda) \quad 48^{\circ} 57^{\prime} 41,98^{\prime \prime}$ W. A altitude ortométrica (h) do vértice do Córrego Alegre é de 683,81 metros.
Segundo Brasil (2005) o elipsoide Hayford de 1924 possui um semi eixo a de 6.378 .338 metros e um achatamento $f$ de $1 / 297$.

\subsubsection{SAD 69}

O segundo SGB a ser implantado no Brasil foi o Datum Sul Americano de 1969 (SAD 69). É um sistema mais recente se comparado com o datum Córrego Alegre.

O início da aplicação e implantação desse sistema de referência foi destacado por Roque et al. (2006):

O sistema de referência exigido pelo INCRA no Brasil é o South American Datum 1969 - SAD-69, que é um sistema geodésico regional de concepção clássica. A sua utilização pelos países sulamericanos foi recomendada em 1969 através da aprovação do relatório final do Grupo de Trabalho sobre o Datum Sul-americano, pelo Comitê de Geodésia reunido na XI Reunião Panamericana de Consulta sobre Cartografia, recomendação não seguida pela totalidade dos países do continente. Tinha como objetivo a unificação do referencial para os trabalhos geodésicos e cartográficos na América do Sul. (ROQUE et al., 2006, p. 93).

Roque et al. (2006) ressaltam em sua pesquisa que, apesar da recomendação imposta em 1969 na XI Reunião Panamericana de Consulta sobre Cartografia, foi somente em 1979 que de fato o SAD 69 se tornou oficialmente o sistema de referência adotado no Brasil em trabalhos que envolvem cartografia e geodésica.

Roque et al. (2006), classificaram o SAD 69 como um sistema regional e clássico, Magna Júnior (2007) explica essas duas características impostas ao sistema de referência em questão.

Para Magna Júnior (2007) um sistema regional e não geocêntrico, se caracteriza pelo deslocamento do centro do elipsoide de referência com relação ao centro de massa da Terra, em busca de melhor adaptação do elipsoide à área de interesse, no caso do SAD 69 a América do Sul.

Em relação a um sistema clássico, Magna Júnior (2007) determina que seja clássico pelo fato de que a realização desses sistemas de referência ocorreu por meio de métodos de posicionamento terrestres, denominados clássicos ou convencionais, citando como exemplo as cadeias de triangulação, poligonação e observações astronômicas.

Dentro da linha de pensamento, Costa (1999) vai ao encontro com as acepções feitas por Magna Júnior (2007) ao afirmar que o método clássico do SAD 
69:

é um sistema implementado antes das técnicas espaciais de posicionamento e baseado em um modelo da Terra de melhor adaptação do respectivo elipsoide ao geoide na América do Sul, recebendo a denominação de sistema geodésico regional ou local, o que caracteriza um deslocamento de dezenas de metros do centro do seu elipsoide com relação ao centro de massa da Terra. Sua orientação espacial foi fornecida pelo azimute geodésico da direção inicial Chuá-Uberaba, segundo o resultado do ajustamento SAD69 (original), obtido mediante a técnica de relaxação de azimute de partida. (COSTA, 1999, p. 84-85).

Para Fischer (1970) o SAD 69 de divide em duas etapas. A primeira se refere ao estabelecimento de um sistema geodésico cujo elipsoide apresente boa adaptação regional ao geoide. A segunda se refere ao ajustamento de uma rede planimétrica de âmbito continental referenciada ao sistema definido. Segundo Fischer (1970) o valor astronômico do SAD 69 é de $271^{\circ} 30^{\prime}$ 05,42" e o valor geodésico é de $271^{\circ} 30^{\prime}$ 04,05”.

$\mathrm{Na}$ discussão sobre as características do SAD 69, destaca-se Costa (1999) que expõe algumas deficiências contidas no sistema, no ajustamento realizado na década de 1960, em que vários países tiveram seus dados criticados, recebendo o mesmo tratamento e avaliação. Deste modo e em função da extensão da rede e das limitações computacionais da época, fez-se necessário a divisão do ajustamento em áreas.

Costa (1999) também ressalta algumas deficiências produzidas pelo sistema ao mencionar que a metodologia adotada para o SAD 69, chamada de "piecemeal", resultou em uma das causas do acúmulo significativo de distorções geométricas (escala e orientação) na rede planimétrica. Costa (1999) também alerta para o fato de que o negligenciamento das reduções das observações geométricas ao elipsoide se constituiu como outro fator para o acúmulo de distorções.

Compreende-se com base em Costa (1999), que estes erros acumulados às coordenadas em SAD 69, foram grandes suficientes para que fosse pesquisada uma nova alternativa mediante as necessidades atuais, pois, de acordo com a autora, as distorções chegaram a atingir até 15 metros nos extremos da rede, surgindo então o sistema de referência SIRGAS 2000.

Perante essa situação de falhas e erros de sobreposição nos extremos, Costa (1999) afirma que:

Tendo em vista os problemas encontrados no SAD69, constatou-se a necessidade de um reajustamento na rede planimétrica, desta vez de forma simultânea e abrangendo todas as observações até o momento. Atualmente dispõe-se de software e máquinas capazes de realizar ajustamento global e simultâneo da rede sendo possível dar um tratamento homogêneo das observações, conhecendo com mais confiabilidade as coordenadas das estações através dos seus respectivos erros absolutos, representados pelo desvio padrão. (COSTA, 1999, p. 88).

Para finalizar a discussão, a autora em sua tese afirma que "Os parâmetros definidores do SAD 69 foram mantidos no reajustamento, sendo alterado somente a metodologia de reajustamento e a inclusão de novas observações, não caracterizando a mudança do referencial definido, apenas do materializado". (COSTA, 1999, p. 86).

Brasil (2005) delimita que o Datum Sul-Americano de 1969 é definido a partir dos parâmetros do Elipsóide Internacional de 1967 que possui um semi eixo maior $\mathrm{a}=6.378 .160$ metros e um achatamento $\mathrm{f}$ $=1 / 298,25$.

Por meio desta discussão constatamos que o SAD 69, constituiu-se como um ótimo sistema de referência para o Brasil, claro que como qualquer outro sistema o SAD 69 também tem suas deficiências e limitações conforme destacado, ainda mais por ser um sistema clássico de 1969, sem a tecnologia avançada presente nos dias atuais. Apresenta-se como uma ótima alternativa para usuários no Brasil voltados principalmente a trabalhos cartográficos e geodésicos necessários para o cadastramento de imóveis rurais.

\subsubsection{SIRGAS 2000}

O terceiro e último sistema de referência aqui detalhado, o Sistema de Referências Geocêntrico para as Américas (SIRGAS 2000), é o adotado atualmente pelo Brasil, possui novas tecnologias que facilitam e oferecem maior precisão aos trabalhos geodésicos e cartográficos.

É caracterizado por ser um sistema com funcionalidade diferente dos dois anteriores, juntos constituem os três sistemas de referência mais utilizados pelo Brasil. Neste momento da pesquisa será exposto como está ocorrendo a densificação do SIRGAS 2000, que vem substituindo o sistema SAD 69. Portanto, vem sendo cada vez mais adotado pelos usuários brasileiros.

Nesta temática da evolução das tecnologias e funcionamento dos sistemas de referência, mais especificamente de como e do porque da passagem do SAD 69 para o SIRGAS 2000 vem sendo realizada, Pereira 
e Augusto (2004) discorrem especificamente sobre esta discussão.

Para Pereira e Augusto (2004), durante os mais de 40 anos da utilização planimétrica dos SGB, foram adotadas diferentes técnicas de posicionamento. No início houve a criação dos métodos clássicos de triangulação, astronômicos e poligonação geodésica para os sistemas de referência mais antigos, como o Córrego Alegre e SAD 69, responsáveis pela determinação de coordenadas em um conjunto de vértices, no qual a ocupação era imprescindível na materialização do Sistema Geodésico de Referência.

Nesse particular é necessário destacar que a geodésia à satélite passou a ser utilizada através do sistema TRANSIT, permitindo pela primeira vez de forma inédita a integração da região Amazônica ao SGB, o referido reajustamento do SAD 69.

Posteriormente, em 1991, de acordo com Pereira e Augusto (2004), o IBGE passou a utilizar exclusivamente o NAVSTAR/GPS (Navigation Satellite with time and Rancing / Global Positioning System), para a densificação da componente planimétrica do SGB, originando a Rede Nacional GPS. Pereira e Augusto (2004) apontam para o fato da criação, em 1996, das redes ativas por meio do monitoramento contínuo de satélites do GPS.

É válido ressaltar que por meio desta rede ativa pode-se implantar o SIRGAS 2000, justamente pelo fato de que o SAD 69, não era compatível com as modernas técnicas de posicionamento, como por exemplo o GPS. Surge então, a proposta de idealização de referência compatível com as modernas técnicas, o SIRGAS 2000:

Paralelamente as diferentes metodologias empregadas, também foram utilizados diferentes sistemas de referência. Atualmente, o sistema de referência adotado é o SAD 69 (South American Datum 1969), definido pela Resolução IBGE - PR no 22, de 21/07/1983 [..] Este sistema de referência entretanto, não é compatível com as modernas técnicas de posicionamento, como por exemplo o GPS. Este fato fez com que o IBGE, em 2000, durante o I Seminário sobre Referencial Geocêntrico no Brasil, apresenta-se proposta de atualização do sistema de referência nacional, através da criação do Projeto Mudança do Referencial Geodésico - PMRG. Este projeto tem como objetivo promover a substituição do sistema de referência atual, o SAD 69, para um novo sistema, compatível com as novas tecnologias de posicionamento e representação, no caso o SIRGAS 2000. (PEREIRA; AUGUSTO, 2004, p. 2)

Conforme exposto, a rede SIRGAS integrou o GPS substituindo o antigo sistema implantado por meio de vários receptores GPS, utilizados durante a campanha SIRGAS (Figura 4).

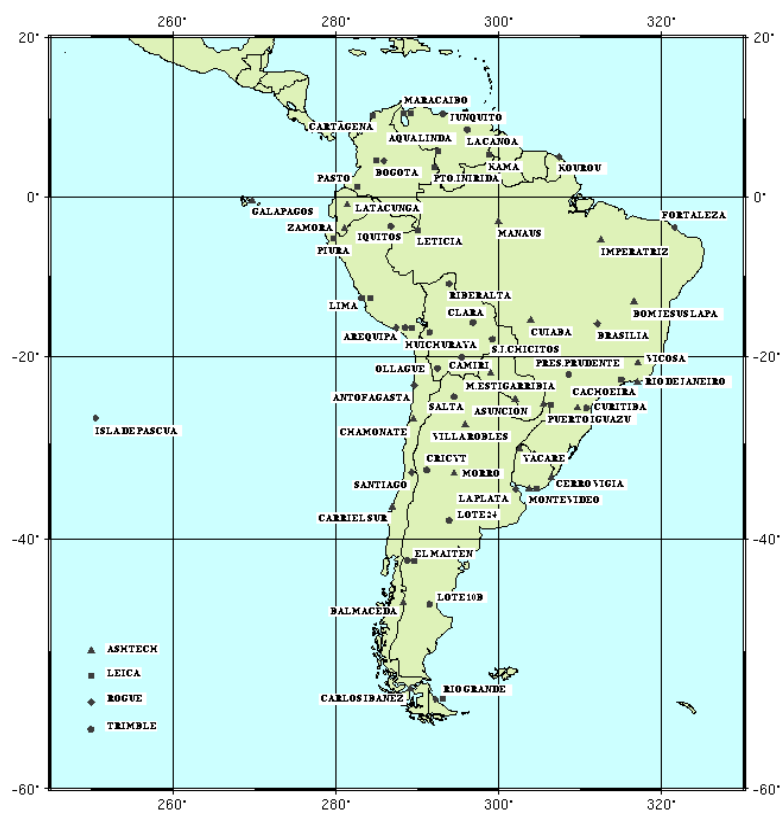

Figura 4: Os diferentes símbolos representam os vários receptores GPS utilizados durante a campanha SIRGAS de 1995. Fonte: Dalazoana (2001, p. 41.)

A figura 5 determina a rede de referência SIRGAS na América do Sul, América Central e América do Norte, os triângulos representam os pontos de referência da campanha SIRGAS 95 e os círculos do SIRGAS 2000 .

No contexto das transformações dos SGB clássicos locais e regionais para um sistema geocêntrico como é o caso do SIRGAS 2000, torna-se interessante analisar obras literárias como a de Augusto et al. (2005), Silveira (2004) e Silveira (2005).

Augusto et al. (2005) relatam que a mudança de sistema trouxe benefícios, principalmente quanto à compatibilidade das informações a nível internacional, os autores revelam que o projeto SIRGAS 2000, teve como objetivo e como fator para que fosse criado, o estabelecimento de um sistema geodésico único para as Américas, com o objetivo de promover e promulgar um novo sistema de referência, mais moderno e de concepção geocêntrica, compatível com as modernas tecnologias de posicionamento.

Silveira (2004) atenta para o fato de que o SIRGAS é uma rede geodésica continental de precisão científica, apoiada em uma rede nacional sul-americana, possibilitando a integração com redes existentes em outros continentes, graças a presença de estações de 
operação contínua pertencentes à Rede Global do International GPS Service for Geodynamics (IGS).

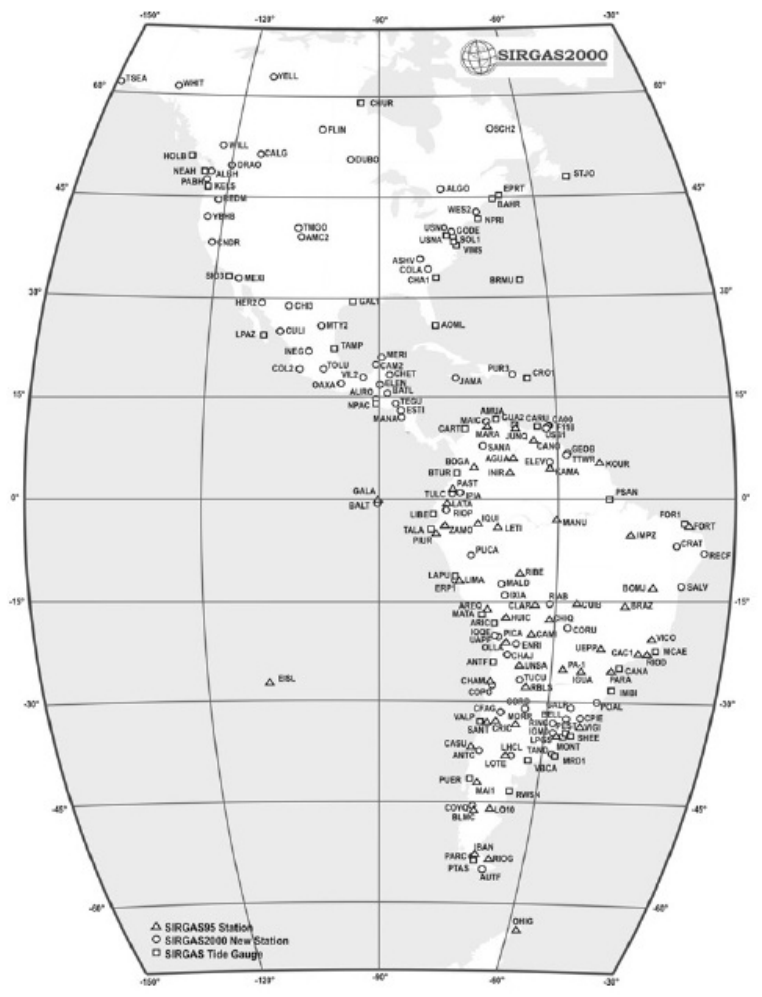

Figura 5: Rede de Referência do SIRGAS

Fonte: www.sirgas.org

Quanto a adoção de um referencial de caráter geocêntrico, Roque et al. (2006) afirma que:

se constitui em uma necessidade, objetivando o atendimento dos padrões globais de posicionamento. Com isto, fica garantida a manutenção da qualidade dos levantamentos GPS realizados em território nacional, uma vez que manter o seu referenciamento ao SAD-69 implica na degradação da precisão. Outro fator determinante diz respeito à necessidade de se buscar uma compatibilidade com os demais países sulamericanos, adotando-se no continente um referencial único para as atividades cartográficas. (ROQUE et al., 2006, p. 93).

Segundo dados divulgados pelo IBGE (2000) o projeto SIRGAS foi originado durante a Conferência Internacional para Definição de um Referencial Geocêntrico para América do Sul, em 1993, na cidade de Assunção, Paraguai.

Por meio do relatório de pesquisa elaborado pelo governo brasileiro, pode-se definir o sistema SIRGAS 2000, como um novo sistema de referência para o SGB e que nos dias atuais, pode ser usado ao mesmo tempo com os sistemas SAD 69 e Córrego Alegre.
No mesmo relatório, BRASIL (2013), nos atentou que o ano previsto para a implementação oficialmente da rede SIRGAS no Brasil foi 2014, até este ano ficou caracterizado uma fase de transição da implementação do SAD 69 para o SIRGAS 2000. Atualmente o SIRGAS 2000 é o único sistema geodésico de referência legalizado no Brasil, sendo possível a conversão dos dados de SAD 69 para SIRGAS 2000.

De maneira sucinta, o projeto SIRGAS “compreende as atividades necessárias à adoção no continente de uma rede de referência de precisão compatível com as técnicas atuais de posicionamento, notadamente as associadas ao Sistema de Posicionamento Global (GPS)." (VOLPI, 2007, p. 44).

Volpi (2007) considera que a utilização de um método criado no passado como o clássico, com métodos de triangulação, poligonação e trilateração, nos dias atuais, em que a precisão é pelo menos dez vezes pior que a fornecida pelo GPS, implica no mínimo, em desperdícios de recursos.

$\mathrm{Na}$ mesma linha de raciocínio de Volpi (2007), Roque et al. (2006) recorrem sobre as mudanças benéficas para os sistemas:

Associado a essa mudança necessária e inevitável tem-se
grandes benefícios e vantagens, dentre as quais pode-se citar:
alcance de precisões a níveis muito melhores que no passado,
compatibilidade de informações a nível internacional, maior
confiabilidade nos resultados e, principalmente, uma maior
facilidade para os usuários quando da integração de novos
levantamentos ao SGB (ROQUE et al., 2006, p. 94).

Segundo Volpi (2007) o projeto SIRGAS foi dividido em duas partes. A primeira objetiva estabelecer um sistema geodésico para que o respectivo elipsoide apresentasse "boa adaptação" regional ao geoide, a segunda parte objetiva ajustar uma rede planimétrica de proporção continental referenciada ao sistema definido.

O projeto SIRGAS teve estabelecido os seguintes objetivos quando criado na Conferência Internacional para Definição de um Datum Geocêntrico para a América do Sul :

a) definir um sistema de referência geocêntrico para a América do Sul;

b) estabelecer e manter uma rede de referência

c) definir e estabelecer um datum geocêntrico. (IBGE, 1997, p.10)

Analisando os objetivos traçados pelo IBGE ao projeto SIRGAS, Moraes et al. (2008, p.3) estabelecem 
as principais características desse sistema. Segundo os autores, o Sistema Geodésico de Referência constituinte é o International Terrestrial Reference System (ITRS). O Elipsóide de referência é o Geodetic Reference System 1980 (GRS80) possuindo um semi eixo maior a de 6.378 .137 metros e um achatamento $f$ de $1 / 298,257222101$. Tem como origem o centro de massa da Terra e orientação aos polos e meridiano de referência consistentes em $\pm 0,005$.

Moraes et al. (2008) também relatam as estações de referência que o sistema SIRGAS 2000 possui estabelecidas no Brasil, totalizando-as em 21, as quais constituem a estrutura de referência do sistema SIRGAS 2000 no território brasileiro.

Sistemas de referência a nível global também são essenciais para o geoprocessamento, como exemplo, podemos citar a rede de referência do IGS (Figura 6) e a ITRF 2008 (Figura 7).

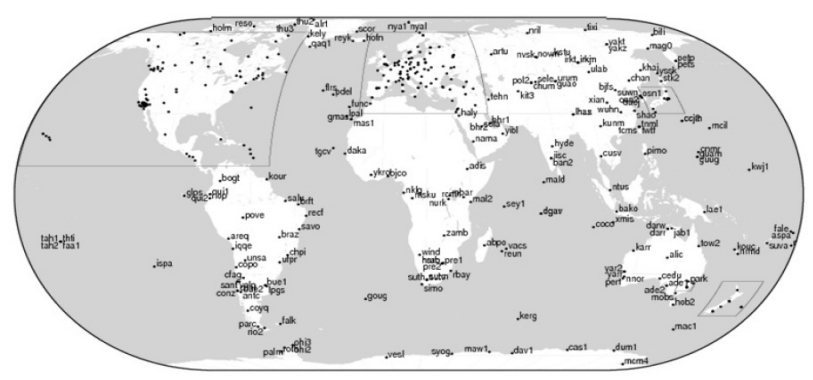

Figura 6: Rede de referência do IGS [Fonte: www.igs.org]. T4 Fonte: Blitzkow et al.(2011, p. 638)

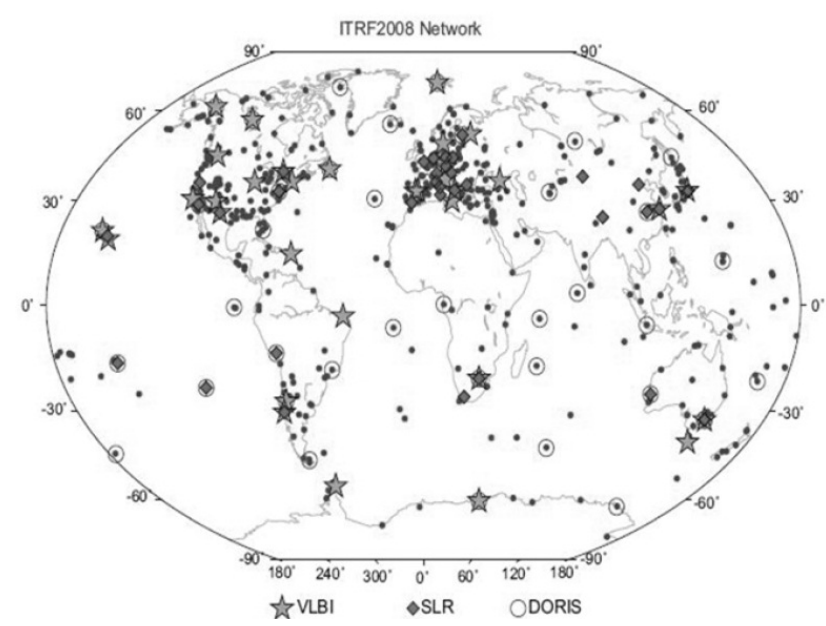

Figura 7: Rede de Referência ITRF 2008 Fonte: Blitzkow et al.(2011, p. 644)

Portanto, foram destacados os sistemas mais utilizados no Brasil, suas características e principais fun- cionalidades. A partir deste momento é necessário analisarmos a lei no 10.267/01 que estabelece parâmetros para utilização dos sistemas de referência no cadastramento de imóveis rurais.

\subsection{Relação do sistema de referência com o cadastramento rural segundo a Lei $n^{\circ} 10.267 / 01$}

É importante relatar também a norma técnica criada para o cadastramento de imóveis rurais, os principais objetivos e recomendações propostas.

Nesse particular, Piovisan et al. (2004, p. 3), destacam a importância da lei $n^{\circ} 4.504$, de 30 de novembro de 1964 que institui o Estatuto da Terra, criando o cadastro imobiliário rural, o qual determinou a realização de um levantamento dos imóveis rurais em todo o país, sob responsabilidade de um órgão federal, neste caso, do INCRA.

Piovisan et al. (2004) citam que por meio desse mecanismo elaborado pelo governo federal, todo proprietário passou a ser obrigado a preencher um formulário, organizado e distribuído pelo INCRA, denominado de declaração para cadastro de imóvel rural. O autor atenta para o fato de que as informações alegadas ao INCRA por parte dos proprietários é de extrema responsabilidade dos mesmos, no caso de omissão, alteração ou falsificação dos dados, que se caracterizam como atitudes de má fé, caberá o pagamento do tributo em dobro, além de multas e custos com verificações.

É importante frisar a importância dos sistemas de referência para que se realize o procedimento do cadastro rural, principalmente no tocante a parte de georreferenciamento, delimitando o território em questão.

A lei $\mathrm{n}^{\circ}$ 10.267/01 altera os dispositivos das leis: 4.947 de 6 de abril de 1966; 5.868 de 12 de dezembro de 1972; 6.015 de 31 de dezembro de 1973; 6.739 de 5 de dezembro de 1979; 9.393 de 19 de dezembro de 1996 e insere outras providências.

Com esta lei, o artigo 176 da lei no 6.015, de 31 de dezembro de 1973, passa a vigorar com as seguintes alterações:

$\int 30$ Nos casos de desmembramento, parcelamento ou remembramento de imóveis rurais, a identificação prevista na alínea a do item 3 do inciso II do $\int 1$ o será obtida a partir de memorial descritivo, assinado por profissional habilitado e com a devida Anotação de Responsabilidade Técnica - ART, contendo as coordenadas dos vértices definidores dos limites dos imóveis rurais, georreferenciadas ao Sistema Geodésico Brasileiro e com precisão posicional a ser fixada pelo INCRA, 
garantida a isenção de custos financeiros aos proprietários de imóveis rurais cuja somatória da área não exceda a quatro módulos fiscais.

\4 o A identificação de que trata o \30 tornar-se-á obrigatória para efetivação de registro, em qualquer situação de transferência de imóvel rural, nos prazos fixados por ato do Poder Executivo (BRASIL, 2001)

Verifica-se então por meio desta alteração a importância do SRB para o desmembramento, parcelamento ou remembramento de imóveis rurais, sendo obrigatoriamente necessário georreferenciar o cadastramento ao Sistema Geodésico Brasileiro com precisão posicional a ser fixada pelo INCRA, no caso, o SIRGAS 2000.

Por meio da lei $\mathrm{n}^{\circ} 10.267 / 01$, o artigo 225 da lei no 6.015 , de 31 de dezembro de 1973, passa a vigorar com as seguintes alterações:

$\int 3^{\circ}$ Nos autos judiciais que versem sobre imóveis rurais, a localização, os limites e as confrontações serão obtidos a partir de memorial descritivo assinado por profissional habilitado e com a devida Anotação de Responsabilidade Técnica - ART, contendo as coordenadas dos vértices definidores dos limites dos imóveis rurais, georreferenciadas ao Sistema Geodésico Brasileiro e com precisão posicional a ser fixada pelo INCRA, garantida a isenção de custos financeiros aos proprietários de imóveis rurais cuja somatória da área não exceda a quatro módulos fiscais (BRASIL, 2001).

Piovisan et al. (2004, p. 1/2) definem o processo de cadastramento de imóveis rurais como sendo a constituição de um banco de dados no qual encontram-se dados referentes a informações sobre estrutura física do imóvel, principalmente informações georreferenciadas sobre seus limites, objetivando, principalmente, à equação de tributos. De acordo com os autores, esse banco de dados é elaborado pelo INCRA, sob responsabilidade do governo federal.

Teixeira (2005, p.3) nos relata que um dos problemas que sempre prejudicou a organização do meio rural foi a grilagem de terras, que atua mais intensamente nas regiões norte e centro oeste do Brasil, mas que também atinge as demais regiões do país. $\mathrm{O}$ autor destaca alguns problemas como a sobreposição de títulos com vários registros sobre a mesma área e a alocação de uma propriedade em local diferente daquele constante do título.

De encontro com as afirmações propostas por Teixeira (2005), Piovisan et al. (2004, p. 1) afirmam que "Em 28 de agosto do ano de 2001, com o objetivo de acabar com a grilagem de terras e a formação ilegal de latifúndios no Brasil, foi aprovada a Lei no 10.267/01".
Pereira e Augusto (2004, p. 1) destacam a importância do sistema de referência a partir da lei $10.267 / 01$. Segundo as autoras, no período pretérito a elaboração da lei, não era obrigatória realizar a referência posicional integrada a uma rede de referência, o sistema consistia em um processo meramente descritivo e sem maior rigor técnico. Dessa forma, a partir de sua aprovação o legislador delimita que a especificação técnica deixa de ser meramente descritiva, passando a exigir também, a precisão posicional.

Esta mudança foi executada por meio da criação do Sistema Público de Registro de Terras, instituído através da lei no 10.267/01, que determina que durante o cadastramento dos imóveis rurais, seja realizada a demarcação dos limites definidos por meio de coordenadas precisas e referenciadas ao Sistema Geodésico Brasileiro, uma medida que objetivou coibir a apropriação irregular e a transferência fraudulenta de terras, nessa linha de raciocínio Pereira e Augusto (2004) determinam que:

De forma a impedir a sobreposição de áreas e identificar as propriedades de forma inequívoca, a lei estabelece no seu Artigo $3^{\circ}$ que os vértices definidores dos limites dos imóveis rurais devem ser georreferenciados ao SGB, sendo que sua precisão posicional foi estabelecida pelo INCRA em 0,5 metros (PEREIRA; AUGUSTO, 2004, p. 2).

Portanto, verifica-se com base nas literaturas aqui indicadas que a lei $\mathrm{n}^{\circ}$ 10.267/01 aprimorou o Cadastro Nacional de Imóveis Rurais (CNIR), e que o processo de cadastramento visa garantir a legitimidade dos títulos das propriedades privadas e terras públicas, pois, segundo dados de Pereira e Augusto (2004), dos 850 milhões de hectares que compõem o território brasileiro, não há informações sobre cerca de 200 milhões no Sistema Nacional de Cadastro dos Imóveis Rurais.

Ainda sobre esta temática da inclusão e importância dos Sistemas de Referência Brasileiros no cadastramento rural definidas pela Lei ${ }^{\circ} 10.267 / 01$, Vettorazzi (2013) determina que:

A Lei 10.267 exige que todo imóvel rural apresente as coordenadas dos vértices definidores de seus limites georreferenciadas ao Sistema Geodésico Brasileiro. Ela é clara também ao afirmar que a identificação do imóvel será obtida a partir de memorial descritivo assinado por profissional habilitado e com a devida Anotação de Responsabilidade Técnica (ART), responsável por elaborar e executar o levantamento que resultará no memorial descritivo. (VETTORAZZI, 2013, p. 3). 
No tocante a Anotação de Responsabilidade Técnica (ART) mencionada por Vettorazzi (2013) e Piovisan et al. (2004, p. 4), os autores argumentam que a realização desses levantamentos devem ser executadas por profissionais habilitados para esse fim e, portanto, passíveis de responder judicialmente por eventuais falhas ocorridas nos procedimentos técnicos, os autores justificam que essa medida pode contribuir para a isenção da responsabilidade do registro imobiliário, sobre possíveis superposições que venham a ocorrer. A determinação do profissional habilitado para realizar esse serviço ficou a cargo do Conselho Federal de Engenharia e Agronomia (CONFEA).

Para finalizar o estudo sobre a referida lei, Piovisan et al. (2004), citam a importância da mesma para um confiável e organizado levantamento topográfico dos imóveis rurais, que deste modo, com a integração dos SGB ruma a um bom caminho:

Logo, para efetivamente entrar em funcionamento, o CNIR depende principalmente da adequação dos estabelecimentos registrais, em relação ao recebimento de memoriais georreferenciados, e sua conferência. Assim como o INCRA também necessita adaptar-se a essa nova realidade. Hoje, pelo que se tem observado, tudo esta caminhando nessa direção, o que poderá gerar bons frutos para toda a sociedade brasileira. (PIOVISAN et. al., 2004, p. 9).

Para a correta implementação do processo de cadastramento rural exposto pela lei $\mathrm{n}^{\mathrm{o}} 10.267 / 01$, o INCRA criou uma norma técnica para georreferenciamento de imóveis rurais, definindo e explicando o modo correto da realização do cadastramento dos imóveis, uma norma criada "Com o propósito de orientar os profissionais que atuam no mercado de demarcação, medição e georreferenciamento de imóveis rurais". (VETTORAZZI, 2013, p. 11)

Desta maneira, Vettorazzi (2013) define a função do geoprocessamento no cadastramento de imóveis rurais, associado à descrição dos imóveis, seus limites, características e confrontações assinadas por um profissional habilitado, contendo na anotação de responsabilidade técnica as coordenadas dos vértices definidores dos limites dos imóveis georreferenciados ao SGB e com precisão posicional definida pelo INCRA.

Em seus capítulos específicos, a norma técnica para georreferenciamento de imóveis rurais (BRASIL, 2010), disserta sobre vértices, padrões de precisão, identificação e reconhecimento de limites do imóvel, materialização dos vértices, levantamento, processamento e tratamento dos dados, apresentação de soluções e documentação requeridas.

Segundo Roque et. al. (2006) o INCRA estabeleceu esta norma técnica justamente para que as propriedades rurais fossem georreferenciadas de forma correta, sem erros de precisão das coordenas, ou seja, com a adoção de um sistema de referência geocêntrico, para que não haja, por exemplo, uma sobreposição dos limites de diferentes propriedades.

De acordo com Vettorazzi (2013, p. 13) o objetivo geral consiste em:

Estabelecer os preceitos técnicos aplicáveis aos serviços de agrimensura, relacionados com as atividades fundiárias, objetivando a caracterização e o georreferenciamento de imóveis rurais por meio do levantamento e materialização de seus limites e posterior certificação desse trabalho junto ao INCRA (VETORAZZI, 2013, p. 13).

Vettorazzi (2013) define os objetivos específicos da norma técnica em três. $\mathrm{O}$ primeiro diz respeito à padronização dos trabalhos de agrimensura destinados ao levantamento de imóveis rurais, de forma a se ter fiel conhecimento da malha fundiária rural do Brasil. O segundo consiste na garantia da confiabilidade na geometria descritiva do imóvel rural, de forma a diminuir conflitos decorrentes de sobreposição de limites com imóveis limítrofes. O terceiro objetivo consiste na definição de padrões técnicos aos profissionais que atuam na área de georreferenciamento de imóveis rurais, para fim de certificação junto ao INCRA.

Mais especificamente sobre os sistemas de referências Pereira e Augusto (2004) de acordo com a norma técnica emitida pelo INCRA, apontam quais estações e redes são admitidas como referências para os levantamentos:

a) redes geodésicas estaduais estabelecidas a partir do rastreamento de sinais de satélites de posicionamento e homologadas pelo IBGE; b) vértices da rede fundamental $\left(1^{\mathrm{a}}\right.$ ordem) brasileira, desde que os mesmos tenham sido reocupados com rastreadores de sinais do GPS, e suas novas coordenadas homologadas pelo IBGE; c) estações ativas receptoras de sinais de satélites do GPS, da Rede Brasileira de Monitoramento Contínuo - RBMC/IBGE; d) estações ativas receptoras de sinais de satélites do GPS, da Rede INCRA de Bases Comunitárias do GPS - RIBaC, quando homologadas; e) estações ativas receptoras de sinais de satélites do GPS, pertencentes a outros órgãos públicos ou empresas privadas, desde que homologadas pelo IBGE; f) linhas de nivelamento geométrico e/ ou redes trigonométricas, quando necessárias ao apoio vertical, homologadas pelo IBGE (PEREIRA; AUGUSTO, p.2). 
Deste modo, verifica-se a importância da criação desta lei, sua respectiva norma técnica e a obrigatoriedade de adotar um SGR para a delimitação dos imóveis rurais. Procedimentos que se mostraram ao longo do tempo, benéficos para o território brasileiro, no sentido de padronizar as técnicas de georreferenciamento com a adoção do sistema de referência geocêntrico SIRGAS 2000. Evitando assim, problemas constantes até então, como grilagem de terras e a formação ilegal de latifúndios no Brasil.

\section{CONSIDERAÇÕES FINAIS}

Conclui-se ao término desta pesquisa, por meio das revisões bibliográficas realizadas, que os sistemas geodésicos de referência constituem-se como imprescindíveis para o pleno sucesso de cadastramento e mapeamento dos limites territoriais de imóveis rurais. Por meio da utilização desses sistemas foram evitados vários problemas de sobreposição de áreas.

Da mesma maneira conclui-se que os sistemas de referência não são importantes somente para o cadastramento de imóveis rurais, apresentam-se essenciais também para trabalhos que envolvam geoprocessamento, que tenham como objetivos o apoio ao mapeamento, demarcação de unidades político-administrativas, obras de engenharia, regulamentação fundiária, entre outros.

Ficou evidente durante a pesquisa que a Lei $n^{\circ}$ 10.267/01 foi implementada com o objetivo de: acabar com a grilagem de terras e a formação ilegal de latifúndios no Brasil, presente em várias regiões do país; cessar a sobreposição de títulos com vários registros sobre a mesma área e, encerrar com alocações de propriedades em locais diferentes daqueles constantes nos títulos.

Verificou-se a importância do SRB para o desmembramento, parcelamento ou remembramento de imóveis rurais, sendo obrigatoriamente necessário georreferenciar o cadastramento ao Sistema Geodésico Brasileiro com precisão posicional fixada pelo INCRA, o SIRGAS 2000.

Averiguou-se que a Lei no 10.267/01 aprimorou o Cadastro Nacional de Imóveis Rurais (CNIR), e que o processo de cadastramento visa garantir a legitimidade dos títulos das propriedades privadas e terras públicas.

Portanto, com a análise desta lei, ficou evidente vários avanços e benefícios, o principal se refere à obrigação de realizar uma referência posicional integrada a uma rede de referência. Anteriormente o sistema de cadastramento de imóveis rurais consistia num sistema meramente descritivo e sem maior rigor técnico. Dessa forma, a partir de sua aprovação a especificação técnica deixou de ser meramente descritiva, passando a exigir também, a precisão posicional, coibindo a apropriação irregular e a transferência fraudulenta de terras.

Quanto aos sistemas geodésicos brasileiros mencionados ao longo do trabalho notou-se que todos apresentaram suas deficiências assim como pontos positivos. O SAD 69 apresentou-se como um ótimo sistema de referencia para o Brasil, sendo adotado pelo INCRA por muito tempo no território brasileiro, mas que não possui a tecnologia avançada dos dias atuais. Este sistema de referencia topocêntrico ainda se apresenta como uma ótima alternativa para usuários no Brasil voltados principalmente a trabalhos cartográficos e geodésicos.

O SIRGAS 2000 começou a ser implementado obrigatoriamente pelo fato de que o SAD 69, não era compatível com as modernas técnicas de posicionamento, como por exemplo, o GPS. Esta mudança de sistema trouxe grandes benefícios, principalmente quanto à compatibilidade das informações a nível internacional, é o sistema de origem geocêntrica é adotado atualmente pelo Brasil.

Concluiu-se então que o projeto SIRGAS 2000 apresentou-se como uma mudança necessária para a aplicação de melhores técnicas de geoprocessamento como o cadastramento de imóveis rurais, pois atingiu um alcance de precisões a níveis mais exatos que no passado.

Grande parte dos produtos cartográficos no Brasil ainda é referenciada ao sistema Córrego Alegre e SAD 69 de origem topocêntrica, mas esse cenário vem se alterando com a criação do SIRGAS 2000 de origem geocêntrica. Verificou-se que a utilização de um método criado no passado, como o clássico, em que a precisão é pelo menos dez vezes pior que a fornecida pelo GPS implica, no mínimo, em desperdícios de recursos.

Portanto, a mudança de um sistema de origem topocêntrica para geocêntrica traz uma série de benefícios e vantagens, dentre as quais pode-se citar: o melhor alcance de compatibilidade de informações a nível internacional; maior confiabilidade nos resultados e, principalmente, maior facilidade para os usuários quando da integração de novos levantamentos ao SGB.

Enfim, de encontro com a proposta inicial desta 
pesquisa, concluiu-se que o cadastramento de imóveis rurais se mostra frágil e incompetente sem a presença de um único sistema geodésico complementar, dessa maneira há uma padronização dos dados referentes ao posicionamento de áreas, evitando os problemas de sobreposição evidenciados.

Foi destacado por meio dos resultados, a partir das análises literárias, que a aplicação dos sistemas de referência facilita o trabalho do usuário e constitui-se como uma ótima ferramenta para mapeamento dos imóveis inseridos no cadastramento rural.

\section{REFERÊNCIAS BIBLIOGRÁFICAS}

AuguSTO, E. A. A.; COSTA, S. M. A.; LIMA, M. A. A.; LOBIANCO, M. C. B.; PEREIRA, K. D.; FORTES, L. P. S. Infra-estrutura Geoespacial Brasileira Moderniza-se. Revista InfoGPS, Curitiba, ano 2, n. 9, 2005.

BLITZKOW, D; MATOS, A. C. O. C; GUIMARÃES, G. N; COSTA, S. M. A. O conceito atual dos referenciais usados em geodésia. Revista Brasileira de Cartografia. Brasília - DF, no 63/5, Edição Especial de Geodésia, p. 633 - 648, 2011.

BRASIL. Lei n ${ }^{\circ}$ 243, de 28 de Fevereiro de 1967, resolução - PR no 22, de 21 de Julho de 1983. Dispõe sobre as Especificações e Normas Gerais para Levantamentos Geodésicos em Território Brasileiro. 1983. Disponível em: < http://www.inde.gov.br/images/inde/ bservico1602.pdf $>$ Acesso em: 08/10/2015

BRASIL. Lei $\mathrm{n}^{\mathrm{o}}$ 10,267 de 28 de Agosto de 2001. Dispõe sobre o cadastramento de imóveis rurais. 2001.Disponível em: <http://www.planalto.gov.br/ ccivil_03/leis/LEIS_2001/L10267.htm > Acesso em: $08 / 10 / 2015$

BRASIL. Artigo 24 do Estatuto aprovado pelo Decreto $n^{\circ} 4.740$, de 13 de junho de 2003. Altera a caracterização do Sistema Geodésico Brasileiro. Rio de Janeiro: IBGE, 2005. Disponível em: <http://www.inde. gov.br/images/inde/rpr_01_25fev2005.pdf $>$ Acesso em: 08/10/2015

BRASIL, MINISTÉRIO DO DESENVOLVIMENTO AGRÁRIO; INCRA, INSTITUTO NACIONAL
DE COLONIZAÇÃO E REFORMA AGRÁRIA. Norma técnica para georreferenciamento de imóveis rurais. $2^{\mathrm{a}}$ ed. Brasília: 2010, 82 f.

BRASIL. Transformação entre o SAD 69 e o SIRGAS 2000 no ArcGIS. Relatório de Pesquisa Tecnomapas. Disponível em: <http://www.geobases.es.gov.br/ portal/attachments/032_SAD69_SIRGAS2000_ArcGis_NTV2.pdf> Acesso em: 08/10/2015.

CHUERUBIM, M. L. Integração de redes GNSS locais ao SIRGAS. 2009. 180p. Dissertação (Mestrado em Ciências Cartográficas). Faculdade de Ciências e Tecnologia, Universidade Estadual Paulista, Presidente Prudente, 2009.

COSTA, S. M. A. Integração da rede geodésica brasileira aos sistemas de referência terrestres. 1999, 156f. Tese (Doutorado em Ciências Geodésicas), Universidade Federal do Paraná, Curitiba, 1999.

DALAZOANA, R. Implicações na Cartografia com a evolução do Sistema Geodésico Brasileiro e futura adoção do SIRGAS. 2001. 122 f. Dissertação (Mestrado em Ciências Geodésicas). Setor de Ciências da Terra, Universidade Federal do Paraná, Curitiba, 2001.

D’ALGE, J. C. L. Cartografia para geoprocessamento. In: CÂMARA, G.; DAVIS, C.; MONTEIRO, A. M. V. Introdução a ciência da geoinformação. São José dos Campos: Instituto Nacional de Pesquisas Especiais (INPE), 2001, Cap. 6, p. 1 - 32.

FISCHER, I. The Development of the South American Datum 1969. The Survey Review. Washington, n. 158, v. 20 , p.354 - 365, 1970 .

IBGE. FUNDAÇÃO INSTITUTO BRASILEIRO DE GEOGRAFIA E ESTATÍSTICA. Sistema de Referência Geocêntrico para a América do Sul. Relatório Final. Grupos de Trabalho I e II. Rio de Janeiro, 1997. $99 \mathrm{p}$.

IBGE. FUNDAÇÃO INSTITUTO BRASILEIRO DE GEOGRAFIA E ESTATÍSTICA. Proposta preliminar para a adoção de um referencial geocêntrico no Brasil. Rio de Janeiro: IBGE, 2000, 29 p. Disponível em: <http://www.ibge.gov.br/home/geociencias/geodesia/pmrg/Historico/seminario_2000/ 
SEMINARIO_2000_PROPOSTA_D.pdf> Acesso em: 08/10/2015.

MAGNA JÚNIOR. J. P. Modelagem de distorções entre realizações de referenciais geodésicos. 2007. 108f. Dissertação (Mestrado em Ciências Cartográficas). Universidade Estadual Paulista, Campus de Presidente Prudente. São Paulo, 2007.

McCARTHY, D. D. IERS Conventions (1996). IERS Technical Note 21, Central Bureau of IERS- Observatoire de Paris, 1996.

MONICO, J. F. G. Posicionamento pelo NAVSTARGPS: descrição, fundamentos e aplicações. $1^{\mathrm{a}} \mathrm{ed}$. São Paulo: Editora UNESP, 2000.

MORAES, I. B. C. M; SILVA, C. C. B; BARBOSA, L. G. Comparação das transformações de coordenadas entre os softwares SPRING 4.3.3 e PCI 9.0. In: SIMPÓSIO BRASILEIRO DE CIÊNCIAS GEODÉSICAS E TECNOLOGIAS DA GEOINFORMAÇÃO. 2., Recife - PE. Anais... Recife: 2008, p. 002-006.

OLIVEIRA L. C. Realizações do Sistema Geodésico Brasileiro Associadas ao SAD 69: Uma Proposta Metodológica de Transformação. 1998. 197f. Tese (Doutorado em Engenharia de Transportes). Escola Politécnica da Universidade de São Paulo São Paulo, 1998.

PEREIRA, K. D; AUGUSTO, M. J. C. O sistema geodésico brasileiro e a lei de georreferenciamento de imóveis rurais. In: SIMPÓSIO DE CIÊNCIAS GEODÉSICAS E TECNOLOGIAS DA GEOINFORMAÇÃO. 1., 2004, Recife - PE. Anais... Recife: SIMGEO, Universidade Federal de Pernambuco, 2004. v. 1.

PIOVESAN, E. C; CAMARGO, P. O; ISHIKAWA, M. I. Lei no 10.267/01 Análise e Aplicação. In: CONGRESSO BRASILEIRO DE CADASTRO TÉCNICOMULTIFINALITÁRIO. 12., Florianópolis - SC. Anais... COBRAC, UFSC, Florianópolis, 2004, 10 f.

ROQUE, C. G; OLIVEIRA, I. C; FIGUEIREDO, P. P; BRUM, E. V. P; CAMARGO, M. F. Georreferenciamento. Revista de Ciências Agro-Ambientais. Alta Floresta, v.4, n.1, p. 87-102, 2006.
SILVEIRA, A. C. Geodésia Aplicada ao Georreferenciamento. Curso de Formação continuada em Georreferenciamento de imóveis rurais. CTET. Março de 2005.

SILVEIRA, L. C. Notícias do IBGE. Revista A Mira, Criciúma, Ano 14, no 123, setembro e outubro de 2004.

TEIXEIRA, C. H. F. Alguns comentários sobre alterações da Lei $\mathrm{n}^{\circ} \mathbf{1 0 . 2 6 7 / 0 1}$. Biblioteca digital da Câmara dos Deputados, Nota técnica, 2005, 6 f. Disponível em: <http://bd.camara.gov.br/bd/bitstream/ handle/bdcamara/1468/alguns_comentarios_teixeira. pdf?sequence $=1>$ Acesso em: 08/10/2015

VETTORAZZI, C. A. Georreferenciamento de imóveis rurais. Materiais didáticos da disciplina topografia e geoprocessamento II. Curso de Engenharia Agronômica da Universidade de São Paulo. 2006.

VOLPI, E. M. Geodésia aplicada ao Georreferenciamento. 2007. 54 f. Especialização (Pós-Graduação em Geoprocessamento para Gestão Urbana e Cadastramento Rural). Fundação Paulista de Tecnologia e Educação, Centro Universitário de Lins, Lins, 2007.

Correspondência dos autores:

Felipe Gomes Rubira

e-mail: felipe_rubira@hotmail.com

Georgea do Vale de Melo

e-mail: georgea.melo@hotmail.com

Gustavo Fonseca

e-mail: gustavofonseca278@gmail.com

Artigo recebido em: 09/10/2015

Revisado pelos autores em: 22/08/2016

Aceito para publicação em: 26/08/2016 